\title{
Dose-Independent Occurrence of Seizure with Tramadol
}

\author{
Haleh Talaie, MD, MPH ${ }^{a}$, Reyhaneh Panahandeh, MDa, Mohammad Reza Fayaznouri, $\mathrm{MD}^{b}$, \\ Zahra Asadi, MSc ${ }^{a}$, Mohammad Abdollahi, PharmD, PhD ${ }^{c}$
}

\author{
aToxicological Research Center, and Poison Center, Loghman-Hakim Hospital, School of Medicine; Shaheed Beheshti University \\ of Medical Sciences, Tehran, Iran \\ bIranian National Center for Addiction Study, Tehran University of Medical Sciences, Tehran, Iran \\ cFaculty of Pharmacy and Pharmaceutical Sciences Research Center, Tehran University of Medical Sciences, Tehran, Iran
}

\begin{abstract}
Introduction: Tramadol, as a centrally-acting, opioid-like analgesic with serotonin reuptake inhibition property, is one of the most prescribed analgesics in the world. We assessed the incidence of seizure, as it is one of the most important adverse effects.

Methods: In a cross-sectional study, 215 cases of tramadol users or abusers who were admitted to Loghman-Hakim Hospital Poisoning Center (LHHPC) in Tehran during a 5-month period, from April 2007 to September 2007, were assessed to evaluate the occurrence of seizure. Patients with positive history of co-ingestion of other drugs, addiction, convulsive disorders, renal diseases, or head trauma with abnormal electroencephalography (EEG) or computerized tomography (CT) scan of the brain were excluded, thus 132 patients were included in the study. For patients who had seizure, CT scan of the brain and EEG were performed, and frequency and type of seizure were identified. Mean tramadol dose was compared between patients with and without seizure.

Results: Among the patients, 97 (73.5\%) were male. Seizure occurred in 61 patients (46.2\%) within 24 hours after tramadol ingestion. The majority of patients who had seizure were male (male, $83.6 \%$ vs. female, $16.4 \%$ ). Mean tramadol dose was lower among females than males (males, $2413 \mathrm{mg}$ vs. females, $1706 \mathrm{mg}$ ), but the difference was not statistically significant. Of 35 patients with documented seizure type, all showed generalized tonic-clonic seizure and 12 patients had abnormal EEG (35.3\%). No statistically significant difference was observed in mean tramadol intake between patients with or without seizure. Analysis of patients with seizure, according to tramadol intake, indicated that most patients used tramadol in the dose range of 500-1000 mg followed in occurrence by 1500-2000 mg, then 100-500 mg, 2500-3000 mg, and 3500-4000 mg.
\end{abstract}

Conclusions: Mean tramadol intake does not differ between patients with and without seizure, and the most common dose range in those with seizure is $500-1000 \mathrm{mg}$. We thus conclude that the incidence of seizure with tramadol is not dose dependent.

Keywords: tramadol, seizure, toxicity

Acknowledgements: This study was supported by the Toxicological Research Center of Loghman-Hakim Hospital. Special thanks to Mr. Emami (clinical research methodologist), Dr. Rasouli (Toxicological Research Center researcher), Mr. Sohrabi (head nurse of poisoning ward of Loghman-Hakim Hospital), Dr. Gharegozli for his assistance in performing the EEG, and centers of EEG and brain CT scanning of Loghman-Hakim Hospital.

Note: This study was supported by a grant from Toxicological Research Center of Shaheed Beheshti University of Medical Sciences and Iranian National Center for Addiction Study of Tehran University of Medical Sciences.

Corresponding Author: Prof. Mohammad Abdollahi, Faculty of Pharmacy, and Pharmaceutical Sciences Research Center, Tehran University of Medical Sciences, Tehran 1417614411, Iran.Email: mohammad.abdollahi@utoronto.ca 


\section{INTRODUCTION}

Tramadol is a centrally-active analgesic acting via both opioid and non-opioid mechanisms that can lead to psychic and physical dependency $[1,2]$. Tramadol has been marketed in the US and Sweden since 1995, and in Germany since 1977. Tramadol has been used in Iran since 1995 [3]. Studies indicate that tramadol is not a good substitute for opioid compounds in reduction of pain or induction of complete euphoria, thus most abusers use tramadol concomitantly with other agents [4-6]. There is evidence that the incidence rate for abuse of tramadol is 69 per thousand persons per year and the dependence rate is 6.9 per thousand persons per year [7]. Prescribed doses of tramadol do not induce the dependency or respiratory depression usually observed in use of traditional opioid receptor agonists [8]. Tramadol has been found to induce dizziness, headache, central nervous system (CNS) stimulation, dysphoria, and seizures $[9,10]$. Overdose has been reported to result in bradycardia, convulsions, respiratory depression, and coma. It is suggested that toxic effects of tramadol are exacerbated by the presence of CNS-depressant compounds [4]. Reports indicate that seizure occurs in patients receiving tramadol within the recommended dose range, but it is more common when patients exceed the recommended doses $[11,12]$. Consumption of selective serotonin reuptake inhibitors (SSRI), tricyclic antidepressants, monoamine oxidase (MAO) inhibitors, or other drugs that reduce seizure threshold might worsen the neurotoxic symptoms of tramadol. Epilepsy, alcohol ingestion, head trauma, and CNS infections have been considered as predisposing factors for tramadol-induced seizure [13]. The neurotoxicity of tramadol mainly occurs within 24 hours postingestion, and $84.6 \%$ of seizures occur within 6 hours after tramadol intake. The minimum dose of tramadol that induces seizure has been reported to be $200 \mathrm{mg}$ in two different studies $[14,15]$. The aim of this study was to evaluate the incidence of seizure among users and abusers of tramadol.

\section{METHODS}

In this cross-sectional study, 215 patients with seizure and positive history of tramadol use were recruited at the Loghman Hakim Hospital Poison Center (LHHPC) during a 5-month period, from April 2007 to September 2007. LHHPC is a unique poison referral center in Tehran, Iran. Every year, about 20,000 patients are admitted to this center. Daily turnover in this center is $80-100$ patients. Based on our pilot study (estimated proportion of $40 \%$ seizure and $95 \%$ confidence interval), the minimum required sample size was calculated to be 164 patients [16-18]. Every patient age $\geq 13$ years, both male and female, with a positive history of tramadol use in the last 24 hours was included in this study. Patients with a positive history of co-ingestion of other drugs, addiction, convulsive disorders, renal diseases, or head trauma with abnormal electroencephalography (EEG) or brain computerized tomography (CT) scan were excluded. All the patients were observed for at least 24 hours after admission. Diagnosis of seizures was determined on the basis of a typical description by witnesses, and confirmed by clinical signs and symptoms suggestive of a postictal phase or by tonguebiting occurring during seizures. Diagnosis of tramadol use or abuse and addiction was based on the reporting of patients or their relatives. For patients with seizures occurring 24 hours after tramadol intake ( 2 half-lives of tramadol), CT scan of the brain and EEG were performed. The demographic (age, sex) and clinical data (tramadol dose, other drug use, seizure) were collected via a questionnaire filled out by a trained practitioner in daily clinical management.

According to the study criteria, 83 patients were excluded and data of 132 patients were analyzed appropriately by Student's $t$ test and Chi-square test. The alpha level of significance was set at 0.05 . Frequency and type of seizures were determined. Mean tramadol dose was compared between patients with and without seizure. The ethical committee of the Shaheed Beheshti University of Medical Sciences (SBU) approved the study protocol.

\section{RESULTS}

As shown in Table 1, 132 patients were included in this study, with a mean age of 24.13 years (range 15-69 years). Among the patients, 97 (73.5\%) were male. Seizure occurred in 61 patients (46.2\%) within 24 hours post-tramadol intake. The majority of patients who had a seizure were male (male, $83.6 \%$ vs. female, $16.4 \%)$. The mean tramadol dose was lower among females than males (males, $2413 \mathrm{mg}$ vs. females, $1706 \mathrm{mg}$ ) but the difference was not statistically significant (Table 2).

Of patients with seizure, 4 used tramadol by prescription, 40 without prescription, and for 17 subjects information was not available. Among patients without seizure, 4 had used tramadol by prescription, 61 without prescription, and information for 6 was missing. From available data, it was not possible to clarify how often patients adhered to physicians' prescribed doses. Of 61 patients with seizure, type of seizure was documented in 35 patients and EEG was performed in 34. Twelve patients (35.3\%) had abnormal EEG findings, whereas 22 patients (64.7\%) had normal EEG.

\section{Table 1: Frequency of Different Age Groups among} Patients with Seizure

\begin{tabular}{lrrrrrr}
\hline & \multicolumn{5}{c}{ Number of patients } \\
\cline { 2 - 8 } Age group & \multicolumn{2}{c}{ Male } & \multicolumn{2}{c}{ Female } & \multicolumn{2}{c}{ Total } \\
\cline { 2 - 8 } & $\mathbf{N}$ & $\%$ & $\mathbf{N}$ & $\%$ & $\mathbf{N}$ & $\%$ \\
\hline $13-20$ years old & 46 & 74.2 & 16 & 25.8 & 62 & 100 \\
\hline 21-30 years old & 43 & 79.6 & 11 & 20.4 & 54 & 100 \\
\hline $31-40$ years old & 3 & 50 & 3 & 50 & 6 & 100 \\
\hline $41-50$ years old & 1 & 50 & 1 & 50 & 2 & 100 \\
\hline $51-60$ years old & 1 & 50 & 1 & 50 & 2 & 100 \\
\hline$>60$ years old & 3 & 50 & 3 & 50 & 6 & 100 \\
\hline Total & 97 & 73.5 & 35 & 26.5 & 132 & 100 \\
\hline
\end{tabular}




\begin{tabular}{|c|c|c|c|c|c|c|c|}
\hline \multirow{2}{*}{$\begin{array}{l}\text { Patients with } \\
\text { tramadol intake }(n=132)\end{array}$} & \multicolumn{2}{|c|}{ Male } & \multicolumn{2}{|c|}{ Female } & \multicolumn{2}{|c|}{ Total } & \multirow[b]{2}{*}{ P value } \\
\hline & $\mathbf{N}$ & $\%$ & $\mathbf{N}$ & $\%$ & $\mathbf{N}$ & $\%$ & \\
\hline Patients with seizure & 51 & 83.6 & 10 & 16.4 & 61 & 46.2 & 0.010 \\
\hline Patients without seizure & 46 & 64.8 & 25 & 35.2 & 71 & 53.8 & 0.015 \\
\hline Tramadol intake, mg mean & \multicolumn{2}{|c|}{2412.62} & \multicolumn{2}{|c|}{1706.06} & \multicolumn{2}{|c|}{2059.35} & \multirow{2}{*}{0.078} \\
\hline$(\mathrm{SD})$ & \multicolumn{2}{|c|}{$(229.70)$} & \multicolumn{2}{|c|}{$(223.01)$} & \multicolumn{2}{|c|}{$(226.04)$} & \\
\hline Age, years mean (SD) & \multicolumn{2}{|c|}{$23.16(9.09)$} & \multicolumn{2}{|c|}{$26.82(14.82)$} & \multicolumn{2}{|c|}{$24.13(10.9)$} & 0.34 \\
\hline
\end{tabular}

Table 3: CT Scan of the Brain and EEG Findings for Patients with Seizure Who Used Tramadol

\begin{tabular}{lcccc}
\hline & \multicolumn{2}{c}{ CT scan of the brain } & \multicolumn{2}{c}{ EEG } \\
\cline { 2 - 5 } $\begin{array}{l}\text { Patients with tramadol use/ } \\
\text { abuse who had seizure }(\mathbf{n}=\mathbf{1 3 2})\end{array}$ & Number & Percentage & Number & Percentage \\
\hline Normal report & 22 & 64.7 & 44 & 97.8 \\
\hline Abnormal report & 12 & 35.3 & 1 & 2.2 \\
\hline
\end{tabular}

$\begin{aligned} & \text { Table 4: Comparison of Tramadol Intake between Patients with and } \\
& \text { without Seizure }\end{aligned}$
\begin{tabular}{lccc}
\hline $\begin{array}{l}\text { Patients with tramadol } \\
\text { intake (n =132) }\end{array}$ & $\begin{array}{c}\text { Patients with } \\
\text { seizure }\end{array}$ & $\begin{array}{c}\text { Patients without } \\
\text { seizure }\end{array}$ & $\begin{array}{c}\text { P } \\
\text { value }\end{array}$ \\
\hline Tramadol intake, mg mean (SD) & $2186.00(280.80)$ & $2241.42(234.67)$ & 0.88 \\
\hline
\end{tabular}

CT scan of the brain was performed in 45 of the patients with seizure; $97.8 \%$ of the scans showed normal findings (Table 3). No statistically significant difference was observed in mean tramadol intake between patients with or without seizure (Table 4). Analysis of patients according to tramadol intake is shown in Table 5, indicating that most patients used tramadol in the dose range of $500-1000 \mathrm{mg}$ followed by $1500-2000 \mathrm{mg}, 100-500 \mathrm{mg}$, $2500-3000 \mathrm{mg}$, and $3500-4000 \mathrm{mg}$. In all cases, tramadol was ingested in a single acute dose.

\section{DISCUSSION}

Seizures associated with tramadol overdose have been previously reported $[19,20]$. Some studies noted occurrence of seizure even in recommended doses [14,21]. Spiller et al. studied 87 patients with tramadol poisoning and described seizures in 7 (8\%) [20]. Gholami et al. studied 337 cases with tramadol-induced adverse reactions and reported seizure in just 9 patients [22]. The high frequency of seizure (46.2\%) in the present study is remarkably different from other studies [23,24]. Jick et al. in 1998 found no increased risk of seizure upon use of tramadol alone
[25], while Gardner et al. found seizures in 1\% of adult tramadol users after the first tramadol prescription [23]. In both studies, patients received tramadol at therapeutic doses. They also found increased risk of seizure in patients in the age range of 25-54 years and in those with a history of alcohol ingestion [24]. This predisposing factor may have been involved in the high incidence of seizures among our study population, but information on alcohol consumption was not available in the present study population because alcoholic beverages are prohibited in Iran, thus even if consumed are not reported by patients. The present data indicates that most patients will have a normal EEG and CT scan of the brain, which is also supported by a previous study indicating the same incidence [26]. Jovanović-Cupić and his colleagues reported that $54.4 \%$ of cases show seizure with use of tramadol in the dose range of 250-2500 mg. They mentioned seizure in $44 \%$ of patients with at least a 5-year history of tramadol use [15]. About $46 \%$ of the present study subjects experienced seizure in the 24-hour period post-consumption of tramadol, which is within 2 half-lives. Marquardt et al. reported that $84.6 \%$ of seizures occurred within 6 hours postingestion of tramadol [14]. In the present study, all the documented seizures were tonic-clonic. 
Table 5: Distribution of Patients According to Tramadol Intake

\begin{tabular}{lccccccc}
\hline & \multicolumn{2}{c}{$\begin{array}{c}\text { Patients } \\
\text { with seizure }\end{array}$} & $\begin{array}{c}\text { Patients } \\
\text { without seizure }\end{array}$ & \multicolumn{2}{c}{ Total } \\
\cline { 2 - 8 } Tramadol intake (mg) & Number & $\%$ & Number & $\%$ & Number & $\%$ \\
\hline $100-500$ & 6 & 12 & 6 & 8.5 & 12 & $10 \%$ \\
\hline $500-1000$ & 18 & 36 & 22 & 31.4 & 403 & $3.3 \%$ \\
\hline $1000-1500$ & 3 & 6 & 5 & 7.14 & 8 & $6.6 \%$ \\
\hline $1500-2000$ & 5 & 10 & 15 & 21.4 & 20 & $16.6 \%$ \\
\hline $2000-2500$ & 3 & 6 & 1 & 1.4 & 4 & $3.3 \%$ \\
\hline $2500-3000$ & 6 & 12 & 8 & 11.4 & 14 & $11.6 \%$ \\
\hline $3500-4000$ & 2 & 4 & 8 & 11.4 & 10 & $8.3 \%$ \\
\hline $4000-4500$ & 0 & 0 & 0 & 0 & 0 & 0 \\
\hline $4500-5000$ & 1 & 2 & 0 & 0 & 1 & $0.8 \%$ \\
\hline $5000-6000$ & 4 & 8 & 0 & 0 & 4 & $3.3 \%$ \\
\hline $6000-7000$ & 1 & 2 & 1 & 1.4 & 2 & $1.6 \%$ \\
\hline $7000-8000$ & 1 & 2 & 2 & 2.8 & 3 & $2.5 \%$ \\
\hline 10,000 & 0 & 0 & 2 & 2.8 & 2 & $1.6 \%$ \\
\hline Total & 11 & & 1 & & 12 & 100 \\
\hline Missing data & 50 & 100 & 70 & 100 & 120 & \\
\hline & & & & & & \\
\hline
\end{tabular}

Jovanović-Cupić noted seizures in 31 (54.4\%) of his study patients; of those, 14 (45\%) were single seizures and 17 (55\%) were multiple seizures [15]. A dose-dependent incidence of seizure has been reported in animals [27], but not reported for humans. As shown in Table 5, the minimum dose of tramadol-associated seizure was $100 \mathrm{mg}$ and the most common dose range for seizure was between 500 and $1000 \mathrm{mg} / \mathrm{kg}$ (33\% of cases). It has been reported in two other studies that $200 \mathrm{mg}$ is the minimum dose to induce seizures $[14,15]$. It appears from our data that the occurrence of seizures in humans is not dose dependent.

A recent study from Tehran indicated that tramadol overdose has been one of the most frequent causes of drug poisoning in recent years, especially in young adult males with a history of substance abuse and mental disorders. In cases in which $>5 \mathrm{~g}$ of tramadol had been ingested, cardiopulmonary arrest was the most common cause of death [28].

One of the interesting findings of this study is that mean tramadol intake did not differ between patients with and without seizure, and the most common dose range to induce seizure was 500-1000 mg. We thus conclude that the incidence of seizures with tramadol in humans is not dose dependent.

Lack of CT scan of the brain and EEG information for all study patients is a limitation of this study. This was due to noncompliance of study subjects in completing examinations and improper follow-up of the hospital staff. Another study limitation was using witness descriptions for determining the presence of seizures, although clinical signs and symptoms were also utilized by the study group. Further studies are necessary to elucidate the relationship between the time postdrug exposure and incidence of seizures.

The authors have no potential financial conflicts of interest to report.

\section{REFERENCES}

1. Frink MC, Hennies HH, Englberger W, et al. Influence of tramadol on neurotransmitter systems of the rat brain. Arzneimittelforschung 1996;46:1029-1036.

2. Lai J, Ma SW, Porreca F, et al. Tramadol, M1 metabolite and enantiomer affinities for cloned human opioid receptors expressed in transfected HN9.10 neuroblastoma cells. Eur J Pharmacol 1996;316:369-372.

3. Nikfar S, Kebriaeezadeh A, Majdzadeh R, Abdollahi M. Monitoring of National Drug Policy (NDP) and its standardized indicators: conformity to decisions of the national drug selecting committee in Iran. BMC Int Health Hum Rights 2005;5:5.

4. De Decker K, Cordonnier J, Jacobs W, et al. Fatal intoxication due to tramadol alone; case report and review of the literature. Forensic Sci Int 2008;175(1):79-82.

5. Preston KL, Jasinski DR, Testa M. Abuse potential and pharmacological comparison of tramadol and morphine. Drug Alcohol Depend 1991;27:7-17. 
6. Cami J, Lamas X, Farre M. Acute effects of tramadol in methadone-maintained volunteers. Drugs 1994;47:39-43.

7. Knisely JS, Campbell ED, Dawson KS, et al. Tramadol postmarketing surveillance in health care professionals. Drug Alcohol Depend 2002;68:15-22.

8. Klotz U. Tramadol-the impact of its pharmacokinetic and pharmacodynamic properties on the clinical management of pain. Arzneimittelforschung 2003;53:681-687.

9. Richter W, Barth H, Flohé L, et al. Clinical investigation on the development of dependence during oral therapy with tramadol. Arzneimittelforschung 1985;35:1742-1744.

10. Shipton EA. Tramadol-present and future. Anaesth Intensive Care 2000;28:363-374.

11. Grond S, Sablotzki A. Clinical pharmacology of tramadol. Clin Pharmacokinet 2004;43:879-923.

12. McDiarmid T, Mackler L, Schneider DM. Clinical inquiries. What is the addiction risk associated with tramadol? J Fam Pract 2005;54:72-73.

13. Clarot F, Goulle JP, Vaz E, et al. Fatal overdoses of tramadol: is benzodiazepine a risk factor of lethality? Forensic Sci Int 2003;134:57-61.

14. Marquardt KA, Alsop JA, Albertson TE. Tramadol exposures reported to statewide poison control system. Ann Pharmacother 2005;39:1039-1044.

15. Jovanović-Cupić V, Martinovic Z, Nesic N. Seizures associated with intoxication and abuse of tramadol. Clin Toxicol (Phila) 2006;44:143-146.

16. Abdollahi M, Jalali N, Sabzevari O, et al. A retrospective study of poisoning in Tehran. J Toxicol/Clin Toxicol 1997;35(4): 387-393.

17. Shadnia S, Esmaily H, Sasanian G, et al. Pattern of acute poisoning in Tehran-Iran in 2003. Hum Exp Toxicol 2007;26: 753-756.
18. Moghadamnia AA, Abdollahi M. An epidemiological study of acute poisonings in northern Islamic Republic of Iran. East Mediterr Health J 2002;8(1):88-94.

19. Kahn LH, Alderfer RJ, Graham DJ. Seizures reported with tramadol. JAMA 1997;278:1661.

20. Spiller HA, Gorman SE, Villalobos D, et al. Prospective multicenter evaluation of tramadol exposure. J Toxicol/Clin Toxicol 1997;35:361-364.

21. Ultram, Ortho-McNeil Pharmaceuticals. Physician's Desk Reference. 53rd ed. Montvale, NJ: Medical Economics, 1999, pp. 2254-2257.

22. Gholami K, Shalviri G, Zarbakhsh A, et al. New guideline for tramadol usage following adverse drug reactions reported to the Iranian Pharmacovigilance Center. Pharmacoepidemiol Drug Saf 2007; 16:229-237.

23. Gardner JS, Blough D, Drinkard CR, Shatin D, et al. Tramadol and seizures: a surveillance study in a managed care population. Pharmacotherapy 2000;20:1423-1431.

24. Gasse C, Derby L, Vasilakis-Scaramozza C, Jick H. Incidence of first-time idiopathic seizures in users of tramadol. Pharmacotherapy 2000;20:629-634.

25. Jick H, Derby LE, Vasilakis C, et al. The risk of seizures associated with tramadol. Pharmacotherapy 1998;18: 607-611.

26. Labate A, Newton MR, Vernon GM, et al. Tramadol and new-onset seizures. Med J Aust 2005;182:42-43.

27. Manocha A, Sharma KK, Mediratta PK. Tramadol, a centrally acting opioid: anticonvulsant effect against maximal electroshock seizure in mice. Indian J Physiol Pharmacol 1998;42:407-411.

28. Shadnia S, Soltaninejad K, Heydari1 K, et al. Tramadol intoxication: a review of 114 cases. Hum Exp Toxicol 2008;27: 201-205. 